\title{
Comparação dos perfis inflamatório e trombótico de pacientes com COVID-19 em seus diferentes desfechos: alta hospitalar e óbito
}

\author{
Comparison of inflammatory and thrombotic profiles of patients with COVID-19 in their different \\ outcomes: hospital discharge and death
}

Comparación de perfiles inflamatorios y trombóticos de pacientes con COVID-19 en sus diferentes desenlaces: alta hospitalaria y muerte

Recebido: 20/01/2022 | Revisado: 25/01/2022 | Aceito: 25/01/2022 | Publicado: 27/01/2022

\author{
Monike Aparecida Matos de Oliveira \\ ORCID: https://orcid.org/0000-0002-6613-2693 \\ Universidade São Judas Tadeu, Brasil \\ E-mail: olliveira.monike@gmail.com \\ Izabella Brito de Souza \\ ORCID: https://orcid.org/0000-0003-1143-5862 \\ Universidade São Judas Tadeu, Brasil \\ E-mail: izabellabs@msn.com \\ Juan Andrade Silva \\ ORCID: https://orcid.org/0000-0001-6048-9459 \\ Instituto Federal São Paulo, Brasil \\ E-mail: juan-andrade@msn.com \\ Carolina Heitmann Mares Azevedo Ribeiro \\ ORCID: https://orcid.org/0000-0002-9457-2733 \\ Universidade Federal do Pará, Brasil \\ E-mail: carolmheitmann@hotmail.com \\ Ana Cristina Lo Prete \\ ORCID: https://orcid.org/0000-0002-2874-5296 \\ Universidade São Judas Tadeu, Brasil \\ E-mail: ana.loprete@saojudas.br
}

\begin{abstract}
Resumo
A COVID-19 foi categorizada como pandemia em março de 2020, sendo manifestada por sintomas respiratórios leves embora haja possibilidade de agravamento e óbito. As causas de morte foram associadas a processos trombóticos e à ativação da coagulação com reação inflamatória exacerbada. Desse modo, o presente estudo objetivou investigar exames do perfil inflamatório, Proteína C Reativa (PCR), e do trombótico, Dímero-D (DD), Tempo de Protrombina (TP), Razão Normalizada Internacional (INR) e Tempo de Tromboplastina Parcial Ativada (TTPa), como marcadores de prognóstico em pacientes com COVID-19 em seus diferentes desfechos. O trabalho consiste em uma análise de exames de pacientes internados com desfecho alta e óbito, com teste molecular positivo para SARS-CoV-2, entre março de 2020 e janeiro de 2021, pertencentes ao repositório COVID-19 Data Sharing/BR do Hospital Beneficência Portuguesa, por meio do teste de Mann-Whitney bicaudal e a correção de Bonferroni. No grupo óbito, 97,7\% dos pacientes estavam com a PCR acima da normalidade e $100 \%$ com DD acima da referência. O TP, no grupo alta, estava acima do normal em $36,21 \%$ dos pacientes, enquanto no óbito, eram $82,8 \%$. O TTPa, no desfecho alta, estava acima da normalidade em 14,8\% dos pacientes, por outro lado, $54,54 \%$ no óbito. Em todos os exames avaliados, as medianas do grupo óbito foram maiores que o grupo alta. Apesar da amostragem ser de um único hospital, tendências importantes foram constatadas. PCR e DD podem ser utilizados como marcadores de prognóstico da COVID-19 e TP, INR e TTPa, embora apresentem resultados relevantes, necessitam de mais investigação.
\end{abstract}

Palavras-chave: COVID-19; Inflamação; Coagulação.

\footnotetext{
Abstract

COVID-19 was categorized as a pandemic in March 2020 and is manifested by mild respiratory symptoms although there is a possibility of worsening and death. The causes of death have been associated with thrombotic processes and activation of coagulation with exacerbated inflammatory reaction. Thus, the present study aimed to investigate tests of the inflammatory profile, C Reactive Protein (CRP), and of the thrombotic profile, D-dimer (DD), Prothrombin Time (PT), International Normalized Ratio (INR) and Activated Partial Thromboplastin Time (TTPa), as prognostic markers in patients with COVID-19 in their different outcomes. The work consists of an analysis of tests from patients admitted with outcome discharge and death, with positive molecular test for SARS-CoV-2, between March 2020 and January 2021, belonging to the COVID-19 Data Sharing/BR repository of the Hospital Beneficência Portuguesa, using the
} 
Mann-Whitney two-tailed test and Bonferroni correction. In the death group, $97.7 \%$ of the patients had a CRP above normality and $100 \%$ had a DD above the reference. The PT, in the discharge group, was above normal in $36.21 \%$ of the patients, while in the death group, it was $82.8 \%$. The TTPa, in the discharge outcome, was above normal in $14.8 \%$ of the patients, on the other hand, $54.54 \%$ at death. In all tests evaluated, the medians of the death group were higher than the discharge group. Although the sample was from a single hospital, important trends were observed. CRP and DD can be used as prognostic markers for COVID-19 and PT, INR and TTPa, although showing relevant results, need further investigation.

Keywords: COVID-19; Inflammation; Coagulation.

\section{Resumen}

El COVID-19 fue clasificado como pandémico en marzo de 2020 y se manifiesta con síntomas respiratorios leves, aunque existe la posibilidad de que se agrave y muera. Las causas de muerte se asociaron a procesos trombóticos y a la activación de la coagulación con reacción inflamatoria exacerbada. Así pues, el presente estudio tenía como objetivo investigar las pruebas del perfil inflamatorio, la proteína $\mathrm{C}$ reactiva (PCR), y del perfil trombótico, el dímero D (DD), el tiempo de protrombina (TP), el cociente internacional normalizado (INR) y el tiempo de tromboplastina parcial activada (TTPa), como marcadores pronósticos en pacientes con COVID-19 en sus diferentes resultados. El trabajo consiste en un análisis de las pruebas de los pacientes ingresados con resultado de alta y muerte, con prueba molecular positiva para SARS-CoV-2, entre marzo de 2020 y enero de 2021, pertenecientes al repositorio COVID-19 Data Sharing/BR del Hospital Beneficencia Portuguesa, mediante la prueba de dos colas de Mann-Whitney y la corrección de Bonferroni. En el grupo de muerte, el $97,7 \%$ de los pacientes tenían una PCR superior a la normalidad y el $100 \%$ tenía una DD superior a la de referencia. La PT, en el grupo de alta, fue superior a la normal en el 36,21\% de los pacientes, mientras que en el grupo de muerte fue del 82,8\%. El TTPa, en el resultado alto, estaba por encima de lo normal en el 14,8\% de los pacientes, por otro lado, el 54,54\% al morir. En todos los exámenes evaluados, las medianas del grupo de muerte fueron mayores que las del grupo de alta. Aunque la muestra procedía de un solo hospital, se observaron tendencias importantes. La PCR y el DD pueden utilizarse como marcadores pronósticos de la COVID-19 y la PT, el INR y la TTPa, aunque muestran resultados relevantes, necesitan más investigación.

Palabras clave: COVID-19; Inflamación; Coagulación.

\section{Introduçãa}

Em 11 de março de 2020, a Organização Mundial da Saúde (OMS) categorizou oficialmente a doença COVID-19 como uma pandemia (Pollard, Morran, \& Nestor-Kalinosk, 2020). A doença foi primeiramente observada em dezembro de 2019, na cidade de Wuhan, província de Hubei, na China, com o aparecimento de casos de uma infecção atípica no trato respiratório superior. O patógeno causador foi posteriormente identificado como SARS-CoV-2, o coronavírus 2 da síndrome respiratória aguda grave (Atzrodt et al., 2020).

Pertencente ao gênero de betacoronavírus, o SARS-CoV-2 apresenta uma fita simples de RNA de sentido positivo (Kadam et al., 2021) e possui estrutura semelhante aos coronavírus envolvidos em outras epidemias, como a síndrome respiratória aguda grave em 2002, ocasionada pelo SARS-CoV-1. O gênero também contém o MERS-CoV, causador da síndrome respiratória do Oriente Médio em 2012 (Kumar et al., 2021).

O coronavírus é caracterizado pela presença de um envelope lipídico, com as proteínas S (spike), M (membrana) e E (envelope), além da proteína do nucleocapsídeo $(\mathrm{N})$, que constitui o capsídeo que aloja seu genoma. A proteína $\mathrm{S}$ que confere ao vírus as saliências em sua superfície, semelhantes a coroas, além de possibilitar a entrada e o reconhecimento da célula hospedeira (Yesudhas et al., 2020). A enzima conversora de angiotensina 2 age como um receptor de membrana celular, mediando a entrada do SARS-CoV-2 na célula humana ao ligar-se à proteína S do vírus (Kumar et al., 2021).

Desde seu aparecimento em 2019, já foram notificados à OMS 328.532.929 casos confirmados de COVID-19 no mundo, com 5.542.359 mortes. Em comparação com os outros países avaliados, atualmente o Brasil ocupa a terceira posição em relação ao número de casos confirmados, contabilizando 23.000.657, e possuindo o segundo maior número de mortes, 621.045 ao total, de acordo com os dados da última atualização, na segunda quinzena de janeiro de 2022 (World Health Organization, 2022).

A principal forma de transmissão da COVID-19 é pelo contato com gotículas que contenham partículas virais, como espirros, tosse e muco, emitidas por indivíduos infectados. Além disso, é possível infectar-se pelo toque na área facial após entrar 
em contato com superfícies contaminadas. A dificuldade de controle e rastreio do vírus deve-se, sobretudo, a tais características de transmissão, semelhantes com surtos de vírus anteriores, juntamente com o fato de indivíduos infectados não apresentarem sintomas de imediato, provocando a gravidade da pandemia (Atzrodt et al., 2020).

A maioria dos casos da doença são descritos como queixas respiratórias leves e autolimitadas, porém, há um subgrupo com um número perceptível de pacientes que desenvolvem condições agravadas, podendo variar de pneumonia e síndrome do desconforto respiratório agudo, até a falência de múltiplos órgãos. Este subgrupo necessita de hospitalização devido à progressão da doença, onde parâmetros laboratoriais poderão ser observados com mais atenção (Eijk et al., 2021). Pode-se considerar que existem indivíduos com mais riscos para apresentar a forma mais grave da doença, sendo eles: portadores de comorbidade (diabetes, obesidade, doenças cardiovasculares, doenças respiratórias crônicas e condições imunocomprometedoras), idosos e homens (Williamson et al., 2020).

Nos pacientes com COVID-19 que evoluíram a óbito, a causa mais comum é a insuficiência respiratória, entretanto, também são causas de morte recorrentes a trombose, a coagulação intravascular disseminada (CID), a falência múltipla de órgãos e a ativação da coagulação com reação inflamatória exacerbada (Asakura et al., 2021).

Para avaliar as respostas inflamatórias agudas, a Proteína C Reativa (PCR), produzida no fígado em resposta ao estímulo da interleucina-6 (IL-6), é uma proteína não específica de fase aguda que eleva sua concentração de forma rápida e considerável durante o processo inflamatório, sendo um biomarcador sensível para esta avaliação (Liu et al., 2020). Geralmente relacionada com doenças reumáticas inflamatórias, tromboembolismo venoso (TEV), doença cardiovascular e lesão renal aguda, altas concentrações da PCR também têm sido associadas a pacientes com COVID-19 em estado grave (Smilowitz et al., 2021).

Nos casos mais severos de COVID-19, a inflamação pulmonar causada pelo SARS-CoV-2 progride para uma tempestade de citocinas, com comprometimento do sistema hemostático, ao provocar profunda ativação e danos nos vasos sanguíneos pulmonares, sendo assim relacionada à alta incidência de TEV (Wool et al., 2021).

Neste sentido, os testes de coagulação também estão envolvidos na avaliação do paciente, especialmente o Dímero-D (DD), Tempo de Protrombina (TP), Razão Normalizada Internacional (do inglês International Normalized Ratio, justificando a sigla utilizada mundialmente, INR) e o Tempo de Tromboplastina Parcial Ativada (TTPa), visto que há vários relatos de prolongamento de TP e TTPa e altos níveis de DD em pacientes que evoluíram à óbito comparado, na admissão, com sobreviventes (Iba et al., 2020). Desta maneira, devido às alterações na coagulação que são observadas nos exames laboratoriais de pacientes com COVID-19, também se tem discutido a associação de níveis elevados de DD com o prognóstico do paciente, relacionando-os com a gravidade da doença (Asakura et al., 2021).

Em razão da seriedade da pandemia atual e da notável associação entre o processo inflamatório e a coagulação com a mortalidade pela COVID-19, é de extrema importância comparar e investigar os exames do perfil inflamatório e trombótico de pacientes com COVID-19 que evoluíram para desfechos diferentes.

Desse modo, o presente trabalho teve como objetivo a investigação do índice inflamatório, por meio da avaliação da PCR, e do índice trombótico, por meio das avaliações de DD, TP, INR e TTPa, como marcadores de prognóstico em pacientes infectados por SARS-CoV-2 que vieram a óbito e que receberam alta hospitalar.

\section{Metodologia}

O presente trabalho se trata de uma análise de dados públicos disponibilizados pelo repositório COVID-19 Data Sharing/BR. O repositório é uma iniciativa da Fundação de Amparo à Pesquisa do Estado de São Paulo (FAPESP), em cooperação com a Universidade de São Paulo (USP), e participação do Instituto Fleury, Hospital Sírio-Libanês, Hospital Beneficência Portuguesa e Hospital Israelita Albert Einstein, com a finalidade de ceder dados relacionados à COVID-19, possibilitando pesquisas nessa temática (FAPESP, 2021). 
Os estudos com análises de bancos de dados públicos têm sido muito utilizados, em especial, na análise de pacientes COVID-19, pois fornecem informação práticas de um número muito elevado de pacientes (Maciel et al., 2021; Ranzani et al., 2021).

O repositório escolhido foi o do Hospital Beneficência Portuguesa, em São Paulo/SP, publicado no dia 28 de abril de 2021 e disponível na página da web para ser baixado. Os dados oferecidos são de exames laboratoriais de pacientes que realizaram testes para COVID-19 a partir de 1 de novembro de 2019, todos representados por identificadores alfanuméricos, um para representar o paciente (ID_Paciente) e outro para representar os tipos de atendimento na instituição (ID_Atendimento), para garantir a anonimidade.

Além disso, o conjunto de dados também dispõe de duas outras planilhas, a "Pacientes", com informações sobre o sexo, ano de nascimento, país, estado, município, região de residência (caracterizado pelos cinco primeiros dígitos do código de endereçamento postal), e a planilha "Desfecho", para informar o desfecho de cada atendimento. Os principais exames disponíveis são dos perfis hematológico, trombótico, renal, cardíaco, hepático e inflamatório, como também os testes sorológicos e moleculares para detecção do SARS-CoV-2, vírus causador da COVID-19.

Para o gerenciamento do banco de dados, foi utilizado o sistema de gerenciamento de dados Microsoft Access (MSAccess) e o Microsoft Excel, sendo necessário a aplicação de filtros e fórmulas. No total, o banco de dados possui 39.000 pacientes com exames e atendimentos variados, sendo assim, como primeiro critério de inclusão para o estudo, foi adicionado no MSAccess a planilha "Exames" com todos os exames dos pacientes (identificados pelo seu "ID_Paciente" único, havendo mudança somente em seu "ID_Atendimento"). Realizou-se um filtro para selecionar apenas os pacientes que realizaram os exames de Coronavírus COVID-19, sendo esses os resultados dos exames moleculares de RT-PCR (Reverse TranscriptionPolymerase Chain Reaction, para o português, Transcrição Reversa da Reação em Cadeia da Polimerase), totalizando 32.382 pacientes.

Subsequentemente, selecionou-se apenas os pacientes que possuíam resultados "reagente", "detectado" e "detectado (positivo)", sendo excluídos os resultados "não detectado", "não detectado (negativo)", "inconclusivo" e "indetectável", resultando em 8.082 pacientes. Visando avaliar exclusivamente o desfecho de pacientes internados, foram utilizados apenas pacientes originados do hospital (HOSP) e excluídos aqueles que fizeram seus exames em laboratórios da instituição (LAB), contabilizando 6.869 pacientes. Essa planilha foi exportada para o Excel e nomeada "COVID-19 positivo".

Concomitantemente, analisou-se a planilha "Desfecho" disponibilizada no repositório, sendo essa dividida em dois arquivos, "Desfecho Óbito" e "Desfecho Alta", no programa Excel. No primeiro grupo foram selecionados apenas óbitos com declaração fornecida pelo Instituto Médico Legal, médico assistente e Serviço de Verificação de Óbito (com dados de tempo menor ou maior que 24 horas de internação), e no segundo, foram selecionados apenas "alta curado" e "alta melhorado". Em ambos os arquivos, foram excluídos os atendimentos provenientes do pronto-socorro, paciente externo e ambulatório, restando apenas o tipo de atendimento internação. A esses pacientes foi inserido uma fórmula que realizou uma busca e seleção dos pacientes da planilha "COVID-19 positivo", totalizando no "Desfecho Óbito" 178 pacientes, e no "Desfecho Alta", 730.

Após essa seleção, no "Desfecho Alta", uma validação de dados foi realizada para verificar se havia algum paciente dessa planilha no "Desfecho Óbito", o que resultou em um total de 727 pacientes com alta hospitalar.

Outra planilha foi criada no MSAccess, selecionando do total de pacientes, apenas os que apresentavam os exames laboratoriais que foram incluídos para análise no presente trabalho, sendo eles: PCR, DD, TP, INR e TTPa, denominando-a "Exames Selecionados". Essa tabela foi exportada para o programa Excel e as informações da planilha "Exames Selecionados" com as planilhas "Desfecho Óbito" e "Desfecho Alta" foram mescladas. Após essa etapa, foram selecionados somente os exames dos pacientes que testaram positivo para o COVID-19 em cada tipo de desfecho. 
A partir desse tratamento de dados, foi possível separar os dois grupos de análise do estudo: os pacientes internados com desfecho óbito, e como controle, os pacientes internados com "alta melhorado" ou "alta curado". Cada exame avaliado foi dividido em uma planilha separada de acordo com o seu desfecho. Para realizar a seleção do último exame em registro do paciente e garantir que representasse seu desfecho, foram estabelecidos dois critérios de exclusão, sendo eles: pacientes em que o último exame disponível fosse superior a 6 dias da data de desfecho e/ou último exame disponível fosse realizado dois dias antes ou mais do resultado positivo para COVID-19. No caso do desfecho óbito, como o repositório não disponibilizou a data de desfecho, foi utilizado o último exame disponível na internação.

Utilizando os critérios descritos, chegou-se aos seguintes resultados: 176 pacientes para análise de PCR, 102 pacientes para DD, 174 pacientes para TP e INR e 176 pacientes para TTPa, todos que vieram a óbito. Para pareamento e comparação, o grupo controle foi estabelecido de acordo com os primeiros pacientes que possuíam exames para os mesmos marcadores e receberam alta melhorado ou alta curado, em ordem alfanumérica, respeitando a quantidade por sexo, até completar o número total encontrado no grupo óbito. Todos os exames foram realizados entre o período de março de 2020 e janeiro de 2021.

A variação do " $n$ " entre as variáveis analisadas se justifica pela aplicação dos critérios de exclusão e, especificamente no caso do DD, também por alguns pacientes não possuírem dados do exame no repositório.

A Figura 1 apresenta o fluxograma com todo o processo de seleção de pacientes do estudo.

Figura 1. Fluxograma do processo de seleção dos pacientes.

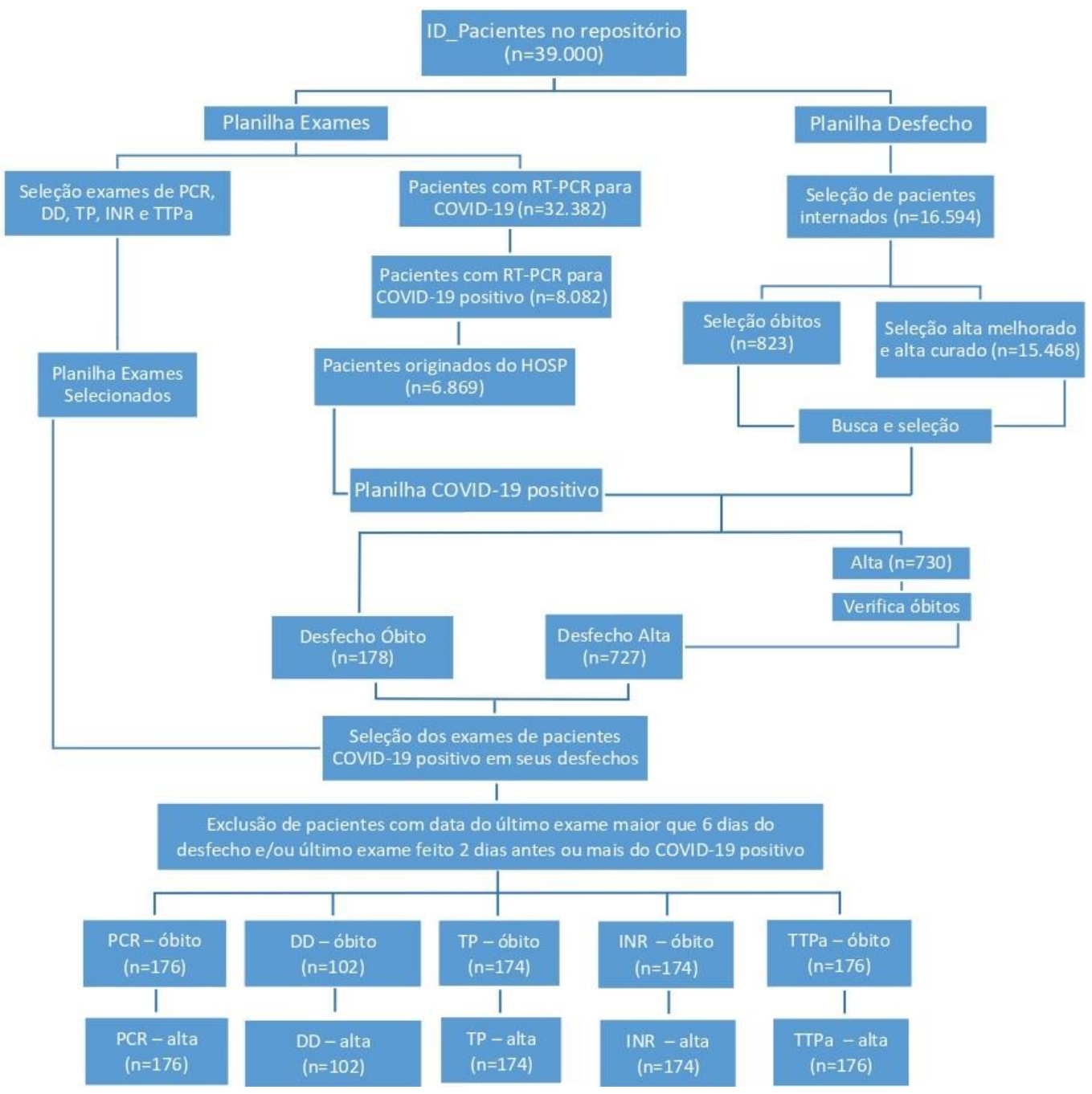

Fonte: Autores (2021). 
A análise estatística do presente trabalho foi realizada através do software $\mathrm{R}$ versão 4.1.2 ( $R$ Foundation for Statistical Computing), no qual foi aplicado o teste de normalidade de Shapiro-Wilk, que apontou a distribuição não normal das cinco variáveis do estudo e, sendo assim, optou-se pelo uso do teste de Mann-Whitney bicaudal para análise dos grupos. As variáveis foram apresentadas como mediana $\left(\mathrm{M}_{\mathrm{d}}\right)$ e variação interquartil (do inglês Interquartile Range - IQR) e verificadas pela correção de Bonferroni, resultando em nível de significância de $\mathrm{p}<0,01$.

Para apresentação dos resultados foi utilizado o programa Microsoft Excel, no qual foram calculadas as porcentagens das variáveis avaliadas, observando se o paciente de cada grupo estava ou não incluso no intervalo válido, de acordo com o Valor de Referência (VR) dos exames a serem analisados. A discussão foi realizada com base em artigos científicos pesquisados na base de dados PubMed, além de consulta a manuais informativos disponibilizados por órgãos de saúde e conselhos de classe.

\section{Resultados e Discussão}

No estudo foram utilizados os exames de desfecho de 176 pacientes para análise de PCR ( 63 femininos e 113 masculinos), 102 pacientes para DD (37 femininos e 65 masculinos), 174 pacientes para TP e INR (62 femininos e 112 masculinos) e 176 pacientes (63 femininos e 113 masculinos) para TTPa. Tais números foram encontrados no grupo desfecho óbito e pareados igualmente, respeitando a quantidade por sexo, para o grupo alta hospitalar.

\section{Perfil inflamatório}

\section{Proteína C Reativa (PCR)}

O parâmetro utilizado para a investigação do perfil inflamatório dos grupos avaliados foi a PCR, que possui VR até $1 \mathrm{mg} / \mathrm{d} \ell$ (Fleury Medicina e Saúde, 2021). A Tabela 1 apresenta a $\mathrm{M}_{\mathrm{d}}$, IQR e as porcentagens de pacientes de acordo com o valor de referência da PCR, em cada um dos desfechos.

Tabela 1. Medianas, variações interquartis e porcentagem de pacientes de acordo com o valor de referência da Proteína C Reativa nos desfechos alta hospitalar e óbito

\begin{tabular}{lcccc}
\hline Desfecho & $\mathbf{M}_{\mathbf{d}}-\mathbf{I Q R}$ & $\begin{array}{c}\text { Abaixo do VR } \\
(<\mathbf{1 m g} / \mathbf{d L})\end{array}$ & $\begin{array}{c}\text { Dentro do VR } \\
(\text { Até } \mathbf{1} \mathbf{~ m g} / \mathbf{d L})\end{array}$ & $\begin{array}{c}\text { Acima do VR } \\
(>\mathbf{1 m g} / \mathbf{d L})\end{array}$ \\
\hline Alta hospitalar & $1,06-2,62$ & - & $47,7 \%(\mathrm{n}=84)$ & $52,3 \%(\mathrm{n}=92)$ \\
Óbito & $15,90-18,70$ & - & $2,3 \%(\mathrm{n}=4)$ & $97,7 \%(\mathrm{n}=172)$ \\
\hline
\end{tabular}

Nota. Valor de referência (VR) retirado do site informativo de exames do Grupo Fleury (Fleury Medicina e Saúde, 2021). Fonte: Autores (2021).

Foi observado que no grupo alta hospitalar ( $\left.\mathrm{M}_{\mathrm{d}} 1,06 \mathrm{e} \mathrm{IQR} 2,62\right), 47,7 \%$ dos pacientes apresentaram resultados dentro do VR ( $n=84$ ), enquanto 52,3\% estavam acima do esperado ( $n=92$ ). Já no grupo óbito ( $M_{d} 15,90$ e IQR 18,70), 97,7\% dos pacientes possuíam PCR acima do esperado $(n=172)$ e apenas 2,3\% estavam dentro da referência $(n=4)$. A figura 2 apresenta a comparação da $\mathrm{M}_{\mathrm{d}}$ e IQR da PCR em ambos os desfechos. 
Figura 2. Comparação das medianas e variações interquartis da Proteína C Reativa nos grupos alta hospitalar e óbito.

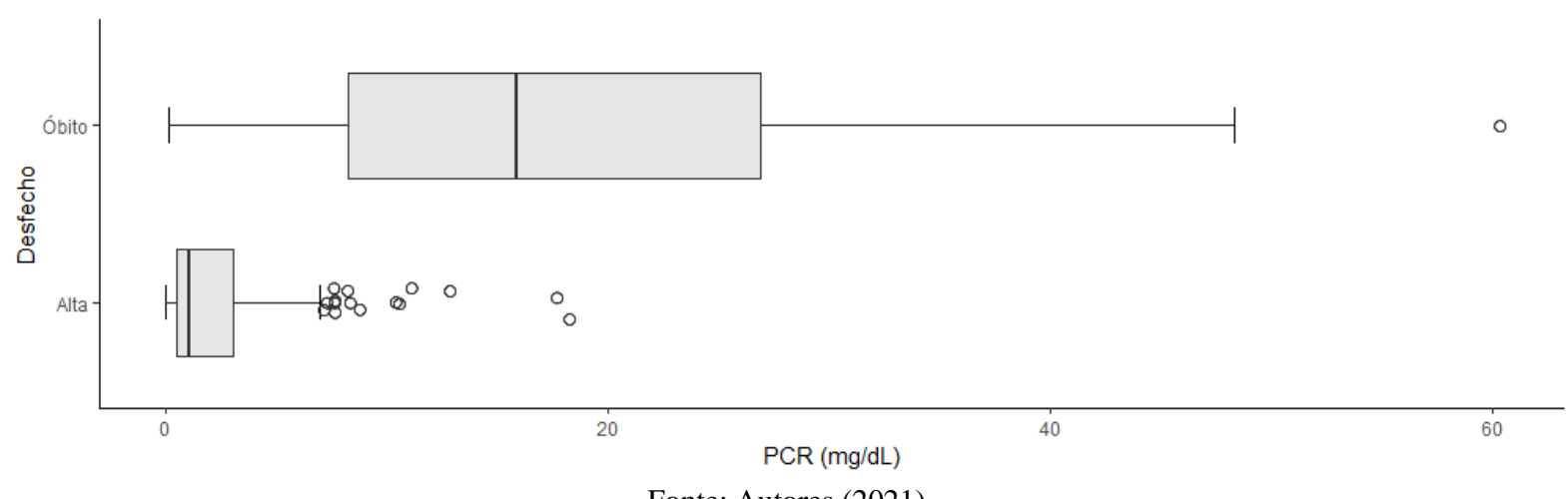

Fonte: Autores (2021).

Tais resultados apontam maior predomínio de valores da PCR acima da referência no grupo óbito em relação ao grupo alta (óbito $97,7 \%$ vs. alta 52,3\%), o que foi confirmado pela análise estatística, que demonstrou maior mediana da PCR no grupo óbito ( $<$ < 0,001; $\mathrm{W}=1857,5)$, estando assim em concordância com achados anteriores disponíveis na literatura.

Guan et al. (2020), em um estudo com 1099 pacientes de diferentes hospitais da China, registraram níveis de PCR elevada em 81,5\% dos casos graves analisados, em comparação com os não graves (56,4\%). Deng et al. (2020) também chegaram a resultados semelhantes comparando casos fatais e recuperados de 225 pacientes em Wuhan, no qual os níveis de PCR do grupo óbito registrados na admissão foram consideravelmente maiores que o grupo recuperado (mediana do grupo óbito: 109,25 mg/ $\ell$ vs. mediana recuperado: $3,22 \mathrm{mg} / \ell$ ) e se mantiveram altos na progressão da doença.

Desta maneira, os resultados do presente estudo corroboram com a hipótese de que a PCR é preditivo de gravidade da COVID-19, o que também foi evidenciado no estudo de coorte retrospectivo de Liu et al. (2020) com 140 pacientes divididos em grupos de leve e alta gravidade, no qual foi confirmado, a partir do modelo de risco proporcional pelo método de Cox, o uso da PCR como fator independente de prognóstico de gravidade da COVID-19, além de apontar maior probabilidade de complicações graves em pacientes com valores da PCR acima de 41,8 mg/ $\ell(4,18 \mathrm{mg} / \mathrm{d} \ell)$.

A correlação entre os altos níveis da PCR e os casos graves de COVID-19 é justificada principalmente pela capacidade da infecção por SARS-CoV-2 provocar resposta imune intensa, denominada “tempestade de citocinas". Esta é caracterizada por uma acentuada ativação celular e produção excessiva de citocinas inflamatórias, ocasionando maior risco de complicações para o paciente (Hu, Huang, \& Yin, 2020; Jin et al, 2020). Tal resposta inflamatória sistêmica tem como marcador a PCR que, em quantidades elevadas, está fortemente relacionada a complicações como TEV e insuficiência renal aguda, ocasionando quadros graves da doença e/ou mortalidade (Smilowitz et al., 2021).

\section{Perfil trombótico}

$\mathrm{Na}$ avaliação do perfil trombótico, foram avaliados os exames de Dímero-D, Tempo de Protrombina, Razão Normalizada Internacional e Tempo de Tromboplastina Parcial Ativada.

\section{Dímero-D}

A tabela 2 apresenta a $M_{d}$, IQR e as porcentagens de pacientes de acordo com o VR do DD, nos desfechos alta hospitalar e óbito. 
Tabela 2. Medianas, variações interquartis e porcentagem de pacientes de acordo com o valor de referência do Dímero-D nos desfechos alta hospitalar e óbito.

\begin{tabular}{lcccc}
\hline Desfecho & $\mathbf{M}_{\mathbf{d}}-\mathbf{I Q R}$ & $\begin{array}{c}\text { Abaixo do VR } \\
(<\mathbf{5 0 0} \mathbf{~} \mathbf{g} / \mathbf{m L})\end{array}$ & $\begin{array}{c}\text { Dentro do VR } \\
(\text { Até } \mathbf{5 0 0} \mathbf{~ n g} / \mathbf{m L})\end{array}$ & $\begin{array}{c}\text { Acima do VR } \\
(>\mathbf{5 0 0} \mathbf{~ n g} / \mathbf{m L})\end{array}$ \\
\hline $\begin{array}{l}\text { Alta hospitalar } \\
\text { Óbito }\end{array}$ & $631-545$ & - & $32,4 \%(\mathrm{n}=33)$ & $67,6 \%(\mathrm{n}=69)$ \\
& $4.936-12.578$ & - & - & $100 \%(\mathrm{n}=102)$ \\
\hline
\end{tabular}

Nota. Valor de referência (VR) retirado do repositório COVID-19 Data Sharing/BR do Hospital Beneficência Portuguesa (FAPESP, 2021). Fonte: Autores (2021).

Quando investigado o DD, que possui VR de até $500 \mathrm{ng} / \mathrm{m} \ell$ (FAPESP, 2021), o grupo alta hospitalar (M 631 e IQR 545) apresentou 32,4\% dos pacientes com resultados na faixa do VR (n=33), enquanto 67,6\% estavam acima deste (n=69). Já no grupo óbito $\left(\mathrm{M}_{\mathrm{d}} 4.936\right.$ e IQR 12.578), 100\% dos pacientes estavam acima do VR (n=102). A Figura 3 apresenta a comparação da $\mathrm{M}_{\mathrm{d}}$ e IQR do DD em ambos os desfechos.

Figura 3. Comparação das medianas e variações interquartis do Dímero-D nos grupos alta hospitalar e óbito.

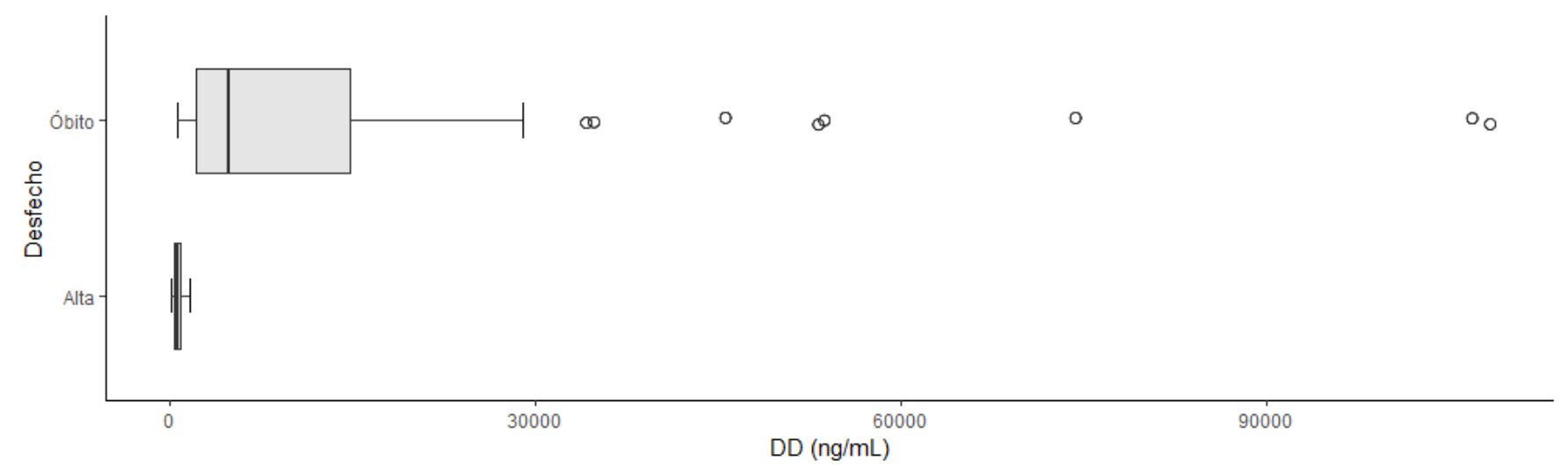

Fonte: Autores (2021).

Os resultados apontam predomínio total de valores acima da referência no grupo óbito em relação ao grupo alta (óbito $100 \%$ vs. alta 67,6\%), sendo confirmado pela análise estatística, que demonstrou uma mediana maior no grupo óbito (p < 0,001 ; $\mathrm{W}=349$ ), estando de acordo com a literatura.

Este marcador é utilizado para avaliar o perfil de coagulação, uma vez que, devido ao sistema fibrinolítico degradar a malha de fibrina posteriormente à formação do coágulo, o DD, um produto da degradação da fibrina, é um ex celente biomarcador de coagulação em pacientes com COVID-19, pois, representa a ativação dos sistemas de coagulação e fibrinólise e, consequentemente, é capaz de determinar a gravidade da doença (Rostami \& Mansouritorghabeh, 2020; Ozen et al., 2021).

Conforme a pesquisa de Tang et al. (2020b), a média de DD em não sobreviventes (n=134) foi de 4,7 $\mu \mathrm{g} / \mathrm{m} \ell$ (4700 $\mathrm{ng} / \mathrm{m} \ell)$, enquanto para sobreviventes $(\mathrm{n}=315)$ foi de $1,47 \mu \mathrm{g} / \mathrm{m} \ell(1470 \mathrm{ng} / \mathrm{m} \ell)$, possuindo um intervalo de normalidade menor que $0,5 \mu \mathrm{g} / \mathrm{m} \ell$ (500ng/m $\ell$ ). De acordo com outro estudo de Tang, Li, Wang \& Sun (2020a), a existência de CID é comum em óbitos com a pneumonia pelo novo coronavírus, ocasionando anormalidade nos resultados de coagulação e DD, de forma elevada, podendo ser utilizado como parâmetro para terapia e avaliação de prognóstico.

O estudo de Ozen et al. (2021) traz também a análise de 120 pacientes que foram observados e divididos em três grupos: sem complicações, pneumonia leve e grave. Dentre eles, 63,3\% dos pacientes obtiveram DD acima de $243 \mathrm{ng} / \mathrm{m} \ell$, sendo uma 
taxa propensa a ascender devido a piora do quadro clínico. Para os pacientes internados na unidade de terapia intensiva com pneumonia grave, $15 \%$ do total, a média foi de $3144,50 \pm 1709,4 \mathrm{ng} / \mathrm{m} \ell$.

Além disso, de acordo com o estudo de Hadid, Kafri e Al-Katib (2021), há um aumento progressivo e constante de DD ocorrendo em pacientes que vieram a óbito devido complicações da COVID-19, contrapondo os pacientes que permaneceram estáveis ou obtiveram melhora significativa, evidenciando que o DD aparenta ser altamente eficaz para o prognóstico, e estabelece relações ainda não comprovadas com o caso mais grave e morte.

No entanto, existem poucos artigos, como é o caso de Asakura e Ogawa (2021), que sugerem a possibilidade de que mesmo havendo uma elevada formação de trombo no corpo, ele pode não estar sendo degradado, o que causaria um aumento leve de DD e, portanto, não seria correlacionado com a gravidade patológica do quadro.

\section{Tempo de Protrombina, Razão Normalizada Internacional e Tempo de Tromboplastina Parcial Ativada}

Os parâmetros TP, INR e TTPa são comumente utilizados na rotina laboratorial como importantes testes de triagem para coagulopatias, sendo desse modo, apresentados de forma conjunta.

A Tabela 3 apresenta $\mathrm{M}_{\mathrm{d}}$ e IQR do TP, bem como as porcentagens de pacientes de acordo com o valor de referência do analito, em ambos os desfechos analisados no estudo.

Tabela 3. Medianas, variações interquartis e porcentagem de pacientes de acordo com o valor de referência do Tempo de Protrombina nos desfechos alta hospitalar e óbito.

\begin{tabular}{lcccc}
\hline Desfecho & $\mathbf{M}_{\mathbf{d}}-\mathbf{I Q R}$ & $\begin{array}{c}\text { Abaixo do VR } \\
(<\mathbf{1 0 , 1})\end{array}$ & $\begin{array}{c}\text { Dentro do VR } \\
(\mathbf{1 0 , 1} \mathbf{a} \mathbf{1 2}, \mathbf{8 s})\end{array}$ & $\begin{array}{c}\text { Acima do VR } \\
(\mathbf{1 2 , 8 s})\end{array}$ \\
\hline Alta hospitalar & $12,60-1,50$ & $1,15 \%(\mathrm{n}=2)$ & $62,64 \%(\mathrm{n}=109)$ & $36,21 \%(\mathrm{n}=63)$ \\
Óbito & $15,60-7,08$ & - & $17,2 \%(\mathrm{n}=30)$ & $82,8 \%(\mathrm{n}=144)$ \\
\hline
\end{tabular}

Nota. Valor de referência (VR) retirado do repositório COVID-19 Data Sharing/BR do Hospital Beneficência Portuguesa (FAPESP, 2021). Fonte: Autores (2021).

Ao observar o TP, que possui VR de 10,1 a 12,8 segundos (FAPESP, 2021), percebe-se que no grupo alta hospitalar $\left(M_{d}\right.$ 12,60 e IQR 1,50), 1,15\% dos pacientes apresentaram resultados abaixo do VR (n=2), enquanto 62,64\% estavam dentro do esperado $(n=109)$ e 36,21\% se encontravam acima do VR (n=63). Já no grupo óbito $\left(M_{d} 15,60\right.$ e IQR 7,08), 17,2\% dos pacientes estão dentro do VR (n=30), enquanto $82,8 \%$ estavam acima do esperado $(n=144)$. A Figura 4 apresenta a comparação da $M_{d}$ e IQR do TP em ambos os desfechos. 
Figura 4. Comparação das medianas e variações interquartis do Tempo de Protrombina nos grupos alta hospitalar e óbito.

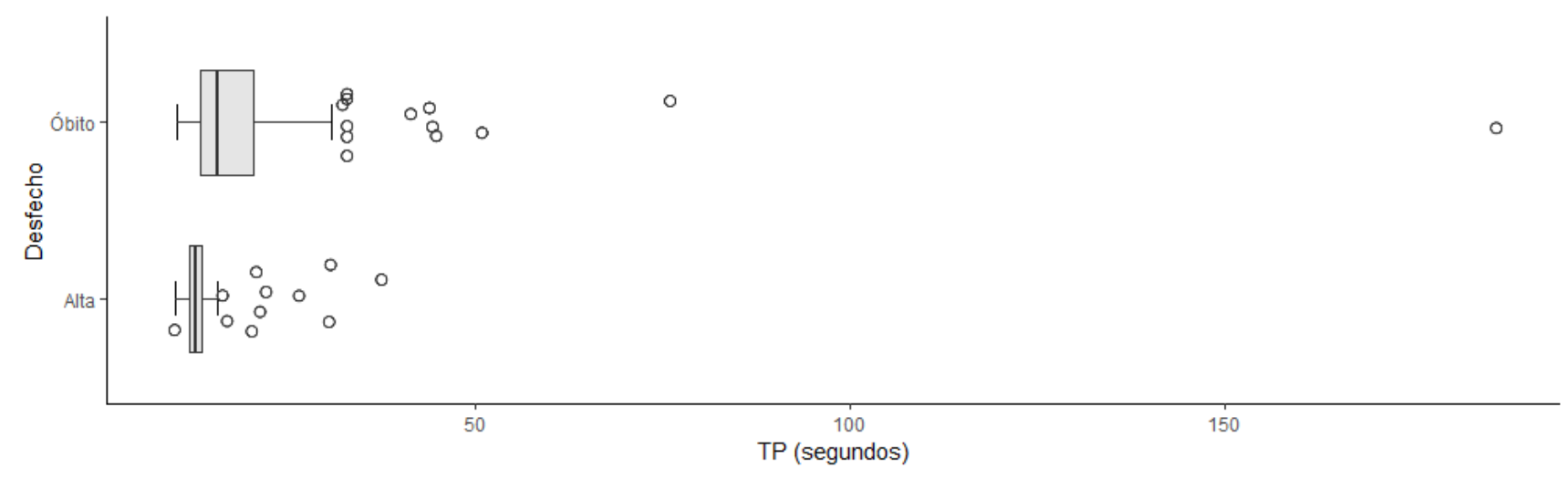

Fonte: Autores (2021).

A Tabela 4 apresenta a $M_{d}$, IQR e as porcentagens de pacientes de acordo com o valor de referência da INR, nos dois grupos.

Tabela 4. Medianas, variações interquartis e porcentagem de pacientes de acordo com o valor de referência da Razão Normalizada Internacional nos desfechos alta hospitalar e óbito

\begin{tabular}{lcccc}
\hline Desfecho & Md - IQR & Abaixo do VR & Dentro do VR & Acima do VR \\
& & $(<\mathbf{0 , 9 s})$ & $(\mathbf{0 , 9}$ a 1,1s $)$ & $(>\mathbf{1 , 1 s})$ \\
\hline Alta hospitalar & $1,10-0,10$ & $1,1 \%(\mathrm{n}=2)$ & $64,4 \%(\mathrm{n}=112)$ & $34,5 \%(\mathrm{n}=60)$ \\
Óbito & $1,40-0,60$ & - & $18,4 \%(\mathrm{n}=32)$ & $81,6 \%(\mathrm{n}=142)$ \\
\hline
\end{tabular}

Nota. Valor de referência (VR) retirado do repositório COVID-19 Data Sharing/BR do Hospital Beneficência Portuguesa (FAPESP, 2021). Fonte: Autores (2021).

Quando avaliado a INR, que possui VR de 0,9 a 1,1 segundos (FAPESP, 2021), é constatado que no grupo alta hospitalar $\left(M_{d} 1,10\right.$ e IQR 0,10) 1,1\% dos pacientes apresentaram resultados abaixo do VR (n=2), enquanto 64,4\% estavam dentro da normalidade $(n=112)$ e 34,5\% encontravam-se acima do VR (n=60). Já no grupo óbito $\left(M_{d} 1,40\right.$ e IQR 0,60), 18,4\% dos pacientes estão dentro dos parâmetros ( $n=32)$, enquanto 81,6\% estavam acima da normalidade ( $n=142)$. A Figura 5 apresenta a comparação da $M_{d}$ e IQR da INR em ambos os desfechos. 
Figura 5. Comparação das medianas e variações interquartis da Razão Normalizada Internacional nos grupos alta hospitalar e óbito.

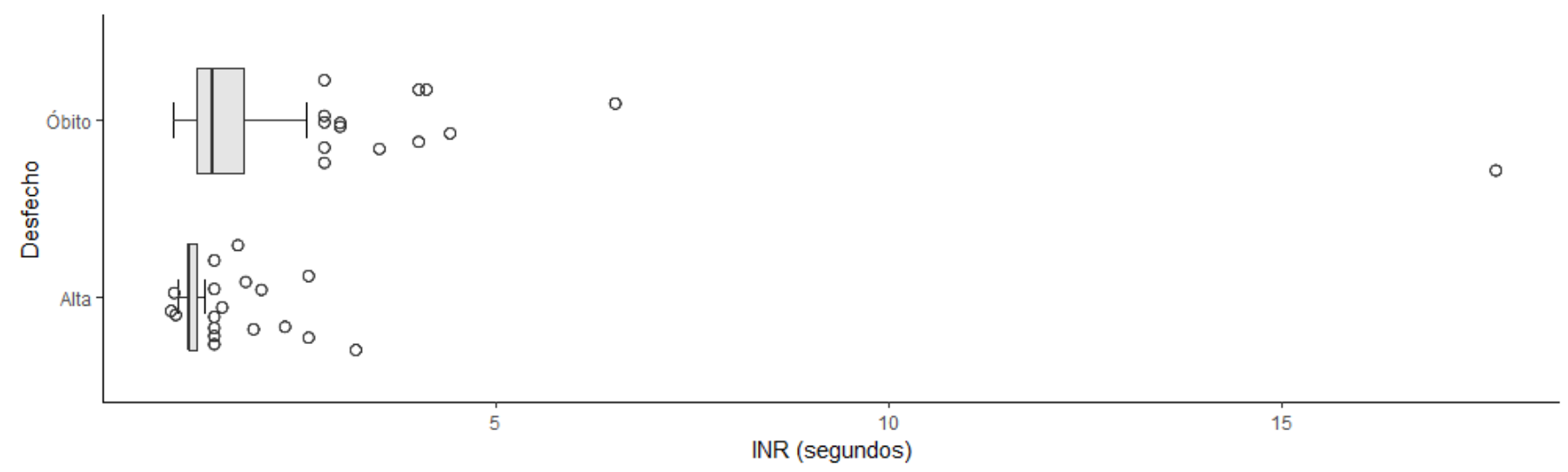

Fonte: Autores (2021).

A Tabela 5 apresenta a $M_{d}$ e IQR do TTPa, assim como as porcentagens de pacientes de acordo com o valor de referência, nos desfechos investigados.

Tabela 5. Medianas, variações interquartis e porcentagem de pacientes de acordo com o valor de referência do Tempo de Tromboplastina Parcial Ativada nos desfechos alta hospitalar e óbito

\begin{tabular}{lcccc}
\hline Desfecho & $\mathbf{M}_{\mathbf{d}}-\mathbf{I Q R}$ & Abaixo do VR & Dentro do VR & Acima do VR \\
& & $(\mathbf{2 5 , 4 s})$ & $(\mathbf{2 5 , 4} \mathbf{a} \mathbf{3 3 , 4 s})$ & $(>\mathbf{3 3 , 4 s})$ \\
\hline Alta hospitalar & $29,20-5,15$ & $13 \%(\mathrm{n}=23)$ & $72,2 \%(\mathrm{n}=127)$ & $14,8 \%(\mathrm{n}=26)$ \\
Óbito & $34,80-17,50$ & $6,82 \%(\mathrm{n}=12)$ & $38,64 \%(\mathrm{n}=68)$ & $54,54 \%(\mathrm{n}=96)$ \\
\hline
\end{tabular}

Nota. Valor de referência (VR) retirado do repositório COVID-19 Data Sharing/BR do Hospital Beneficência Portuguesa (FAPESP, 2021). Fonte: Autores (2021).

Ao analisar o TTPa, que possui VR de 25,4 a 33,4 segundos (FAPESP, 2021), entende-se que o grupo alta hospitalar $\left(\mathrm{M}_{\mathrm{d}} 29,20\right.$ e IQR 5,15), possui 13\% dos pacientes com resultados abaixo da normalidade ( $\mathrm{n}=23$ ), enquanto $72,2 \%$ estavam dentro do esperado $(n=127)$ e 14,8\% encontravam-se acima do VR (n=26). Já no grupo óbito $\left(\mathrm{M}_{\mathrm{d}} 34,80\right.$ e IQR 17,50), 6,82\% dos pacientes estão abaixo do VR $(n=12)$, enquanto 38,64\% dos pacientes estavam dentro do esperado (n=68) e 54,54\% estavam acima do VR (n=96). A figura 6 apresenta a comparação da $M_{d}$ e IQR do TTPa em ambos os desfechos. 
Figura 6. Comparação das medianas e variações interquartis do Tempo de Tromboplastina Parcial Ativada nos grupos alta hospitalar e óbito.

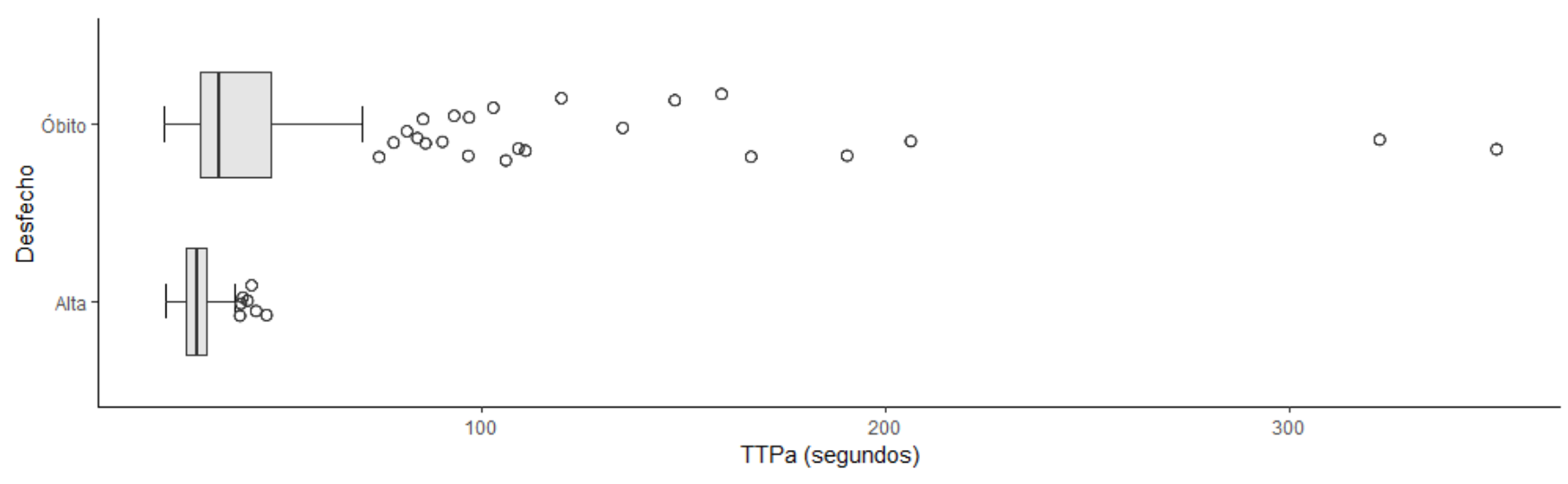

Fonte: Autores (2021).

Os parâmetros TP, INR e TTPa são utilizados para avaliar distúrbios da coagulação, uma vez que, enquanto o TP avalia as vias extrínseca e comum da coagulação, o TTPa avalia as vias intrínseca e comum e, a INR, padroniza os resultados de TP (Ministério da Saúde, 2016).

De acordo com os apontamentos dos resultados, houve predomínio de valores acima da referência no grupo óbito em relação ao grupo alta, para o TP (óbito 82,8\% vs. alta 36,21\%), INR (óbito 81,6\% vs. alta 34,5\%) e TTPa (óbito 54,54\% vs. alta 14,8\%), demonstrado pela análise estatística, que assegurou a diferença entre as medianas de cada desfecho avaliado, sendo maiores no grupo óbito, no TP ( $<<0,001 ; \mathrm{W}=5866)$, no INR $(\mathrm{p}<0,001 ; \mathrm{W}=6054,5)$ e no TTPa $(\mathrm{p}<0,001 ; \mathrm{W}=7848,5)$.

O predomínio de pacientes com TP e TTPa prolongados e, consequentemente, valores de INR acima da referência, também foi observado na literatura. Tang et al. (2020a), em um estudo com 183 pacientes de um hospital em Wuhan, relataram, na admissão, maior TP e TTPa no grupo de não sobreviventes em comparação com os sobreviventes e ainda que dos pacientes não sobreviventes, $71,4 \%$ se adequaram aos critérios de coagulação intravascular disseminada enquanto apenas $0,6 \%$ dos sobreviventes atenderam aos mesmos critérios, apontando que é comum o desenvolvimento de CID em pacientes com óbito por COVID-19.

Jin et al. (2020) também corroboram com tais achados, a partir de uma investigação em 147 pacientes do hospital Wuhan Leishenshan na China, em que demonstraram que os pacientes do grupo óbito possuíam valores significativamente maiores de TP, INR e TTPa do que no grupo de sobreviventes. Além disso, há relatos de que cerca de 20 a $50 \%$ dos pacientes hospitalizados manifestam alterações na coagulação, tais como TP prolongado e trombocitopenia, assim como o DD, já mencionado, sendo resultados associados ao TEV (Gómez-Mesa, Galindo-Coral, Montes, \& Martin, 2021).

A hipercoagulabilidade, caracterizada por trombocitopenia, evidenciada por níveis aumentados de DD, fibrinogênio, fator VIII e Fator de Von Willebrand e TP e TTPa prolongados, se explica, sobretudo, pela resposta imunotrombótica do hospedeiro a patógenos, na qual há a ativação de vários sistemas, como a imunidade inata e a hemostasia. Quando desregulada, a resposta imunotrombótica pode resultar em danos secundários intermediados pela formação de trombos e, em estágio mais avançado, evoluir para CID (Orsi et al., 2020). Autópsias minimamente invasivas em óbitos provocados por COVID-19, realizados por Dolhnikoff et al. (2020) no Hospital das Clínicas da Faculdade de Medicina da USP, também apontaram o estado de hipercoagulabilidade nos pacientes críticos, visto que as amostras histológicas dos pulmões indicam alta frequência de microtrombose pulmonar. 
Desse modo, em consonância com as recomendações da Sociedade Brasileira de Trombose e Hemostasia juntamente com a Associação Brasileira de Hematologia, Hemoterapia e Terapia Celular, se faz necessário o monitoramento regular desses marcadores nos pacientes hospitalizados, sendo fundamental no controle de complicações trombóticas e mortes por COVID-19.

No entanto, embora seja notável a alteração na hemostasia provocada pelo SARS-CoV-2, principalmente nos pacientes mais graves, ainda são necessárias mais pesquisas para determinar o valor prognóstico independente de cada um dos marcadores de coagulação.

Em síntese, de acordo com o teste de Mann-Whitney, há diferença estatística entre os desfechos analisados em cada exame e as medianas do grupo óbito são maiores que o grupo alta hospitalar.

Além disso, o número elevado de óbitos no sexo masculino também é uma observação relevante, pois, quando realizada a seleção de pacientes do repositório, chegou-se no total de 178 pacientes com desfecho óbito válidos para a análise do estudo, e ao separá-los por sexo, foi observado que $35,96 \%$ eram do sexo feminino (n=64), enquanto a maioria, $64,04 \%$, eram do masculino ( $\mathrm{n}=114)$. Tal observação está de acordo com outros estudos disponíveis na literatura que apontam o sexo masculino como um fator de risco para mortalidade por COVID-19 (Williamson et al., 2020).

Outro aspecto relevante é que o repositório COVID-19 Data Sharing/BR do Hospital Beneficência Portuguesa não ofereceu outros dados de prontuário dos pacientes e, sendo assim, não foi possível avaliar o impacto de fatores, como comorbidades, uso de medicamentos e histórico do paciente, que podem interferir nos resultados dos exames laboratoriais investigados no presente estudo.

\section{Conclusão}

Em vista da importante relevância ao pesquisar sobre os perfis inflamatório e trombótico em pacientes com COVID19, os resultados obtidos por meio de análises do repositório COVID-19 Data Sharing/BR do Hospital Beneficência Portuguesa promovem interessantes discussões para profissionais da área da saúde e indivíduos do meio acadêmico, pois, evidenciaram alterações relevantes e significativas nos achados laboratoriais em ambos os grupos estudados, óbito e alta hospitalar.

Como observado ao decorrer das análises, apesar da amostragem ser de um único hospital e, desse modo, não necessariamente refletir o ocorrido em outras localidades, as discussões sobre os parâmetros PCR, DD, TP, INR e TTPa apontam a consolidação dos marcadores PCR e DD como preditores do prognóstico de pacientes com COVID-19. Já em relação aos exames TP, INR e TTPa, apesar de não expressarem claras evidências como marcadores independentes e demandarem mais pesquisas, trouxeram tendências de resultados relevantes, que devem ser consideradas na avaliação da gravidade do quadro de infecção pelo vírus.

Desse modo, em decorrência da doença causada pelo SARS-CoV-2 ser recente, e assim, consequentemente as suas complicações clínicas, novos estudos com amostragens maiores são ainda necessários para melhor esclarecimento das alterações inflamatórias e trombóticas causadas pela COVID-19.

\section{Referências}

Asakura, H., \& Ogawa, H. (2021). COVID-19-associated coagulopathy and disseminated intravascular coagulation. International Journal of Hematology, 113, 45-57, 2021. https://doi.org/10.1007/s12185-020-03029-y.

Atzrodt, C. L., Maknojia, I., McCarthy, R. D. P., Oldfield, T. M., Po, J., Ta, K. T. L., Stepp, H. E., \& Clements, T. P. (2020). A Guide to COVID-19: a global pandemic caused by the novel coronavirus SARS-CoV-2. The FEBS Journal, 287, 3633-3650. https://doi.org/10.1111/febs.15375.

Deng, Y., Liu, W., Liu, K., Fang, Y-Y., Shang, J., Zhou, L., Wang, K., Leng, F., Wei, S., Chen, L., \& Liu, H-G. (2020). Clinical characteristics of fatal and recovered cases of coronavirus disease 2019 in Wuhan, China: a retrospective study. Chinese Medical Journal, $133(11)$, 1261-1267. https://doi.org/10.1097/CM9.0000000000000824. 
Dolhnikoff, M., Duarte-Neto, A. N., Monteiro, R. A. A., Silva, L. F. F., Oliveira, E. P., Saldiva, P. H. N., Mauad, T., \& Negri, E. M. (2020). Pathological evidence of pulmonary thrombotic phenomena in severe COVID-19. Journal of Thrombosis and Haemostasis, 18(6), 1517-1519. https://doi.org/10.1111/jth.14844.

Eijk, L. E. van, Binkhorst, M., Bourgonje, A. R., Offringa, A. K., Mulder, D. J., Bos, E. M., Kolundzic, N., Abdulle, A. E., Voort, P. H. J. van der, Rikkert, M. G. M. O., Hoeven, J. G. van der, Dunnen, W. F. A. den, Hillebrands, J.-L., Goor, H. van (2021). COVID-19: immunopathology, pathophysiological mechanisms, and treatment options. The Journal of Pathology, 254(4), 307-331, 2021. https://doi.org/10.1002/path.5642.

FAPESP (2020). FAPESP COVID-19 Data Sharing/BR. https://repositoriodatasharingfapesp.uspdigital.usp.br/, em 15 de agosto de 2021.

Fleury Medicina e Saúde (2021). Proteína C Reativa, soro. https://www.fleury.com.br/medico/exames/proteina-c-reativa-soro, em 31 de outubro de 2021.

Gómez-Mesa, J. E., Galindo-Coral, S., Montes, M. C., \& Martin, A. J. M. (2021). Thrombosis and Coagulopathy in COVID-19. Current Problems in Cardiology, 46(3), 100742. https://doi.org/10.1016/j.cpcardiol.2020.100742.

Guan, W.-J., Ni, Z.-Y., Hu, Y., Liang, W.-H., Ou, C.-Q., He,J.-X., Liu, L., Shan, H., Lei, C.-L., Hui, D. S.C., Du, B., Li, L.-J., Zeng, G., Yuen, K.-Y., Chen, R.C., Tang, C.-L., Wang, T., Chen, P.-Y., Xiang, J., ... \& Zhong, N.-S. (2020). Clinical Characteristics of Coronavirus Disease 2019 in China. The New England Journal of Medicine, 382(18), 1708-1720. https://doi.org/10.1056/NEJMoa2002032.

Hadid, T., Kafri, Z., \& Al-Katib, A. (2021). Coagulation and anticoagulation in COVID-19. Blood Reviews, 47, 100761. https://doi.org/10.1016/j.blre.2020.100761.

Hu, B., Huang, S., \& Yin, L. (2020). The cytokine storm and COVID-19. Journal of Medical Virology, 93, 250-256. https://doi.org/10.1002/jmv.26232.

Iba, T., Levy, J. H., Levi, M., \& Thachil, J. (2020). Coagulopathy in COVID-19. Journal of Thrombosis and Haemostasis, 18(9), 2103-2109. https://doi.org/10.1111/jth.14975.

Jin, X., Duan, Y., Bao, T., Gu, J., Chen, Y., Li, Y., Mao, S., Chen, Y., \& Xie, W. (2020). The values of coagulation function in COVID-19 patients. PLos One, 15(10), e0241329. https://doi.org/10.1371/journal.pone.0241329.

Kadam, S. B., Sukhramani, G. S., Bishnoi, P., Pable, A. A., \& Barvkar, V. T. (2021). SARS-CoV-2, the pandemic coronavirus: Molecular and structural insights. Journal of Basic Microbiology, 61(3), 180-202. https://doi.org/10.1002/jobm.202000537.

Kumar, A., Prasoon, P., Kumari, C., Pareek, V., Faiq, M. A., Narayan, R. K., Kulandhasamy, M., \& Kant, K. (2021). SARS-CoV-2-specific virulence factors in COVID-19. Journal of Medical Virology, 93(3), 1343-1350. https://doi.org/10.1002/jmv.26615.

Liu, F., Li, L., Xu, M., Wu, J., Luo, D., Zhu, Y., Li, B., Song, X., \& Zhou, X. (2020). Prognostic value of interleukin-6, C-reactive protein, and procalcitonin in patients with COVID-19. Journal of Clinical Virology, 127, 104370. https://doi.org/10.1016/j.jcv.2020.104370.

Maciel, E.L., Jabor, P., Goncalves Júnior, E., Siqueira, P.C., Prado, T.N. \& Zandonade, E. Estudo da qualidade dos Dados do Painel COVID-19 para crianças, adolescente e jovens, Espírito Santo - Brasil, 2020 (2021). Esc Anna Nery, 25(spe):e20200509. doi: https://doi.org/10.1590/2177-9465-EAN-2020-0509

Ministério da Saúde. (2016). Manual de Diagnóstico Laboratorial das Coagulopatias Hereditárias e Plaquetopatias. Ministério da Saúde, Secretaria de Atenção à Saúde. Brasília, DF. https://bvsms.saude.gov.br/bvs/publicacoes/manual_diagnostico_coagulopatias_hereditarias_plaqueopatias.pdf, em 31 de outubro de 2021

Orsi, F. A., Paula, E. V. de, Santos, F. O., Teruchkin, M. M., Campêlo, D. H. C., Mello, T. T., Chindamo, M. C. Macedo, A. V. S., Rocha, A T., Ramacciotti, E., Nascimento, A. C. K., Annichino-Bizzacchi, J., Lourenco, D. M., Guerra, J. C. de C., Rezende, S. M., \& Cavalheiro, C., F ${ }^{\circ}$. (2020). Guidance on diagnosis, prevention and treatment of thromboembolic complications in COVID-19: a position paper of the Brazilian Society of Thrombosis and Hemostasis and the Thrombosis and Hemostasis Committee of the Brazilian Association of Hematology, Hemotherapy and Cellular Therapy. Hematology, Transfusion and Cell Therapy, 42(4), 300-308, 2020. https://doi.org/10.1016/j.htct.2020.06.001.

Ozen, M., Yilmaz, A. Cakmak, V., Beyoglu, R., Oskay, A., Seyit, M., \& Senol, H. (2021). D-Dimer as a potential biomarker for disease severity in COVID-19. The American Journal of Emergency Medicine, 40, 55-59. https://doi.org/10.1016/j.ajem.2020.12.023.

Pollard, C. A., Morran, M. P., \& Nestor-Kalinosk, A. L. (2020). The COVID-19 pandemic: a global health crisis. Physiol Genomics, 52, 549-557. https://doi.org/10.1152/physiolgenomics.00089.2020.

Ranzani, O.T., Bastos, L.S.L., Gelli, J.G.M., Marchesi, J.F., Baião, F., Hamacher, S. \& Bozza, F.A. (2021). Characterisation of the first 250000 hospital admissions for COVID-19 in Brazil: a retrospective analysis of nationwide data. The Lancet Respiratory Medicine, .9(4), 407-418. doi: https://doi.org/10.1016/S2213-2600(20)30560-9

Rostami, M., \& Mansouritorghabeh, H. (2020). D-dimer level in COVID-19 infection: a systematic review. Expert Review of Hematology, 13(11), 1265-1275, 2020. https://doi.org/10.1080/17474086.2020.1831383.

Smilowitz, N. R., Kunichoff, D., Garshick, M., Shah, B., Pillinger, M., Hochman, J. S., \& Berger, J. S. (2021). C-reactive protein and clinical outcomes in patients with COVID-19. European Heart Journal, 42(23), 2270-2279. https://doi.org/10.1093/eurheartj/ehaa1103.

Tang, N., Li, D., Wang, X., \& Sun, Z. (2020a). Abnormal coagulation parameters are associated with poor prognosis in patients with novel coronavirus pneumonia. Journal of Thrombosis and Haemostasis, 18(4), 844-847. https://doi.org/10.1111/jth.14768.

Tang, N., Bai, H., Chen, X., Gong, J., Li, D., \& Sun, Z. (2020b). Anticoagulant treatment is associated with decreased mortality in severe coronavirus disease 2019 patients with coagulopathy. Journal of Thrombosis and Haemostasis, 18(5), 1094-1099. https://doi.org/10.1111/jth.14817.

Williamson, E. J., Walker, A. J., Bhaskaran, K., Bacon, S., Bates, C., Morton, C. E., Curtis, H. J., Mehrkar, A., Evans, D., Inglesby, P., Cockburn, J., McDonald, H. I., MacKenna, B., Tomlinson, L., Douglas, I. J., Rentsch, C. T., Mathur, R., Wong, A. Y. S., Grieve, R., \& Goldacre, B. (2020). Factors associated with COVID-19-related death using OpenSAFELY. Nature, 584(7821), 430-436. https://doi.org/10.1038/s41586-020-2521-4. 
Research, Society and Development, v. 11, n. 2, e34311225990, 2022 (CC BY 4.0) | ISSN 2525-3409 | DOI: http://dx.doi.org/10.33448/rsd-v11i2.25990

Wool, G. D., \& Miller, J. L. (2021) The Impact of COVID-19 Disease on Platelets and Coagulation. Pathobiology, 88(1), 15-27. https://doi.org/10.1159/000512007.

World Health Organization (2022). Who Coronavirus (COVID-19) Dashboard. covid19.who.int, em 19 de janeiro de 2022.

Yesudhas, D., Srivastava, A., \& Gromiha, M. M. (2020). COVID-19 outbreak: history, mechanism, transmission, structural studies and therapeutics. Springer Link, 49, 199-213. https://doi.org/10.1007/s15010-020-01516-2. 